\title{
A Sensitive Ultra-Fast Bioanalytical Method for the Quantification of Rabeprazole in Human Plasma
}

\author{
Shankar S. Velan, Suneetha Vuppu* \\ Industrial Biotechnology Division, School of Biosciences and Technology, Vellore Institute of Technology, Vellore, Tamil Nadu-632014, India.
}

\begin{tabular}{|c|c|}
\hline ARTICLE INFO & ABSTRACT \\
\hline Article history: & \multirow{11}{*}{$\begin{array}{l}\text { A highly sensitive ultra-fast LC-MS/MS based bioanalytical method for the measurement of Rabeprazole in } \\
\text { human plasma was developed and validated using }{ }^{13} \mathrm{C}-\mathrm{D}_{3} \text {-Rabeprazole as internal standard. Rabeprazole is a } \\
\text { sulfabenzimidazole class of compounds, setting chromatography for these classes of compounds is always a } \\
\text { challenge. Rabeprazole was extracted from human plasma samples by liquid-liquid extraction (LLE) and } \\
\text { separated on a short reverse phase Ascentis }{ }^{\circledR} \text { Express C18, } 50 \mathrm{~mm} \times 4.6 \mathrm{~mm}, 2.7 \mu \mathrm{m} \text { column by isocratic elution } \\
\text { with } 40 \% 10 \mathrm{mM} \text { ammonium acetate solution and } 60 \% \text { acetonitrile at a flow rate of } 0.700 \mathrm{~mL} / \mathrm{min} \text {. Rabeprazole } \\
\text { and its labeled internal standard were detected by multiple reaction monitoring (MRM) mode using electro spray } \\
\text { ionization (ESI). All the validation parameters as per current guidelines like specificity, selectivity, accuracy, } \\
\text { precision, recovery, matrix factor, haemolysis effect and stability are assessed in human plasma. Rabeprazole } \\
\text { was found to be linear over a range of } 0.1 \mathrm{ng} / \mathrm{mL} \text { to } 150 \mathrm{ng} / \mathrm{mL} \text { in human plasma. LLOQ of } 0.1 \mathrm{ng} / \mathrm{mL} \text { is } \\
\text { sensitive enough for application to different clinical studies. The intra- and inter-day precision was less than } \\
10 \% \text { and accuracy was within }-3.33 \text { to } 10.00 \% \text {. Recovery }(70 \%) \text { was consistent across the linear dynamic range } \\
\text { of the method. The validated method is a simple, accurate, precise and robust to measure Rabeprazole in human } \\
\text { plasma and could be used for application to any format of clinical studies. }\end{array}$} \\
\hline Received on: 15/01/2016 & \\
\hline Revised on: 22/02/2016 & \\
\hline Accepted on: 30/04/2016 & \\
\hline Available online: $28 / 07 / 2016$ & \\
\hline Key words: & \\
\hline Rabeprazole, Ultra-fast, & \\
\hline Isocratic elution, Stability, & \\
\hline & \\
\hline & \\
\hline & \\
\hline
\end{tabular}

\section{INTRODUCTION}

Rabeprazole,2-[[[4-(3-methoxypropoxy)-3 -methyl-2pyridinyl]-methyl]sulfinyl]-1H-benzimidazole is a selective and irreversible benzimidazole proton-pump inhibitor Figure. 1. Rabeprazole is a prodrug and getsactivated in the acid environment of the parietal cells to active sulphenamide (Ramakrishna et al., 2005; Richardson et al., 1998). Rabeprazole effectively neutralizes and controls the gastric acid secretion by precise inhibition of the hydrogen-potassium adenosine triphosphatase $\left(\mathrm{H}^{+}, \mathrm{K}^{+}\right.$-ATPase $)$enzyme system found at the secretory surface of parietal cells. It inhibits the final transport of hydrogen ions (via exchange with potassium ions) into the gastric lumen. Since, $\mathrm{H}^{+}, \mathrm{K}^{+}$-ATPase enzyme system is regarded as the

\footnotetext{
* Corresponding Author

Suneetha Vuppu, Industrial Biotechnology Division,School of

Biosciences and Technology, Vellore Institute of Technology, Vellore,

Tamil Nadu-632014India.Email: vsuneetha@vit.ac.in
}

acid (proton) pump of the gastric mucosa, rabeprazole is known as a gastric acid pump inhibitor. Rabeprazole has advantage over other similar drugs by not having any anticholinergic or histamine $\mathrm{H}_{2}$-receptor antagonist properties. Several researchers have published methods for the quantification of rabeprazole using HPLC with UV detection (Nakai et al., 1994; Shankar and Suneetha, 2014; Steene et al., 2008), spectrophotometric, (Gindy et al., 2003) and liquid chromatography-tandem mass spectrometry (LC-MS/MS) methods (Zhang et al., 2004). Researchers have also reported the stability studies of rabeprazole under different conditions such as acidic, alkaline, oxidative and photolysis (Gindy et al., 2003). Though, more sensitive and selective HPLC and LCMS/MS methods have been reported for the quantification of rabeprazole, there is a need for an ultra-fast, cost effective, validated bioanalytical method (FDA Guidance, 2001) which addresses the recent regulatory expectations for the application to various clinical studies by LC-MS/MS. 


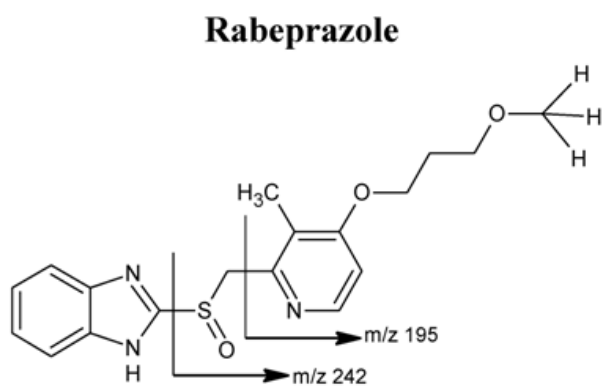

${ }^{13} \mathrm{C}_{-} \mathbf{D}_{3}$-Rabeprazole

Fig. 1: structures.

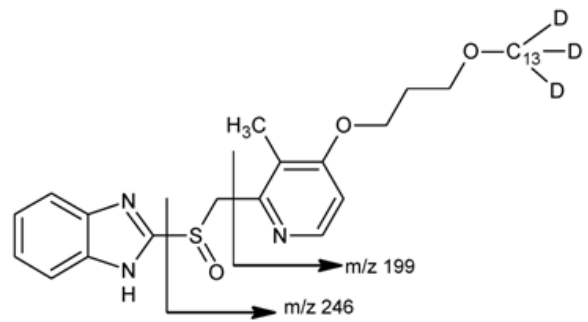

Rabeprazole

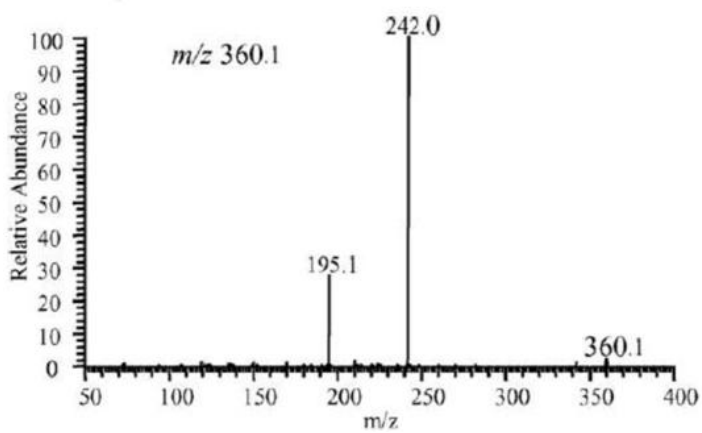

${ }^{13}$ C-D - -Rabeprazole

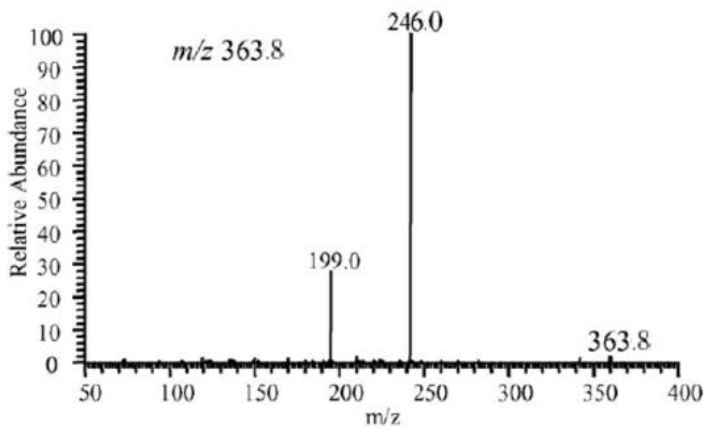

Fig. 2: LC-MS/MS Spectra fragmentation patten.

\section{EXPERIMENTAL}

\section{Chemicals and Reagents}

Ammonium acetate HPLC grade ( $\geq 99 \%)$ sourced from Sigma Aldrich, Potassium di-hydrogen orthophosphate, potassium hydroxide chemicals of analytical grade, acetonitrile, n-hexane and tert-Butyl methyl etherof HPLC grade solvents from Merck Chemicals. Milli-Q water HPLC grade obtained from Milli-Q ${ }^{\circledR}$ system. Working Standards of Rabeprazole and ${ }^{13} \mathrm{C}_{-} \mathrm{D}_{3^{-}}$ Rabeprazole (internal standard) was procured from Sigma Aldrich and Clearsynth, respectively.

\section{Instrumentation}

Waters Xevo TQ-S tandem triple quadrupole mass spectrometer system equipped with an Electrospray ionization (ESI) source and ACQUITY UPLC System comprising of Binary Solvent Manager, a Sample Manager with integral Column Heater, and a Solvent Tray. (Waters India Pvt. Ltd). Data acquisition, Peak integration and quantification were performed using MassLynx ${ }^{\mathrm{TM}}$ version 4.1. Other instruments used were Refrigerated Centrifuge, Deep freezer/ Freezer (Thermo Electron Corporation), Microbalance MX5 and Semi microbalance XP205 (Metler Toledo), Milli-Q ${ }^{\circledR} \quad$ water system from Merck-Millipore, Sample concentrator Zymark's TurboVap LV from Caliper Life Sciences.

\section{LC-MS/MS}

Liquid chromatographic separation of rabeprazole and its internal standard was achieved by isocratic elution on Ascentis ${ }^{\circledR}$ Express $\mathrm{C}_{18}(50 \mathrm{~mm} \times 4.6 \mathrm{~mm}, 2.7 \mu \mathrm{m})$ analytical column attached with a $\mathrm{C}_{18}$ Security Guard column $(5 \mathrm{~mm} \times 4.6 \mathrm{~mm}, 2.7 \mu \mathrm{m}$; Sigma Aldrich's Supelco) operating at $30{ }^{\circ} \mathrm{C}$.Mobile phase used for isocratic elution was a mixture of 40 parts of $10 \mathrm{mM}$ ammonium acetate solution and60 parts of acetonitrile. Flow rate of mobile phase was optimized at $0.7 \mathrm{~mL} / \mathrm{min}$. The mass spectrometer was operated in positive electrospray ionization mode with unit mass resolution and the analytes were detected by multiple reaction monitoring (MRM). MRM transition for rabeprazole and ${ }^{13} \mathrm{C}_{-} \mathrm{D}_{3}$-Rabeprazole (IS) are $m / z, 360.1 \rightarrow 242$ and $m / z \quad 363.8 \rightarrow 246$, respectively. Figure2, shows the product ion spectra of $[\mathrm{M}+\mathrm{H}]^{+}$of rabeprazole and ${ }^{13} \mathrm{C}-\mathrm{D}_{3}$-Rabeprazole.

\section{Sample Preparation}

A liquid-liquid extraction (LLE) method was developed for the extraction of rabeprazole and its internal standard from plasma. To a200 $\mu \mathrm{L}$ aliquot of plasma sample, $10 \mu \mathrm{L}$ of internal standard (50 ng/mL ${ }^{13} \mathrm{C}_{-} \mathrm{D}_{3}$-Rabeprazole in diluent) and $500 \mu \mathrm{L}$ of phosphate buffer ( $\mathrm{pH} 7.0)$ were added. The samples were mixed thoroughly and $2.5 \mathrm{~mL}$ mixture of extraction solution (n-hexane: tert-Butyl methyl ether (55:45, v/v)) was added.

All samples were vortex mixed 1500 rpmfor 10 minutes and centrifuged at $4,000 \mathrm{rpm}$ at $4{ }^{\circ} \mathrm{C}$ for 5 minutes. A $2 \mathrm{~mL}$ of organic supernatant was separated and dried under a stream of nitrogen at $50{ }^{\circ} \mathrm{C}$. The dried extract was reconstituted with $100 \mu \mathrm{L}$ of mobile phase and transferred into polypropylene inserts in $1 \mathrm{~mL}$ shell vials capped with polyethylene plugs. An aliquot of $5 \mu \mathrm{L}$ of the sample was injected into LC-MS/MS system for analysis. 


\section{Calibration Standards and Quality Control Samples}

Stock solution of rabeprazole was prepared in diluent (50\% acetonitrile in Milli- $\mathrm{Q}^{\circledR}$ water) at the concentration of 400 $\mu \mathrm{g} / \mathrm{mL}$. Stock solution of internal standard was prepared in acetonitrile at the concentration of $400 \mu \mathrm{g} / \mathrm{mL}$ and diluted to prepare a working solution of $50 \mathrm{ng} / \mathrm{mL}$ using diluent. Calibration standards of rabeprazole were prepared by spiking calibration standard solution in the interference-free blank plasma at $0.1,0.2$, $0.6,2.5,12.5,25,50,100$ and $150 \mathrm{ng} / \mathrm{mL}$ concentrations. Similarly, the quality control (QC) samples were prepared using an another independent stock solution of rabeprazole to obtain the plasma concentrations of $0.3,60$ and $120 \mathrm{ng} / \mathrm{mL}$, representing low, medium and high concentration of QC samples, respectively. The aqueous stock, diluted standard and quality control solutions of rabeprazole and internal standard were stored at +2 to $+8{ }^{\circ} \mathrm{C}$. The spiked plasma samples (calibration standards and quality controls) samples were stored either at -20 or $-70{ }^{\circ} \mathrm{C}$ until used.

\section{Method Validation}

Plasma samples were quantified by peak area ratio method (peak area of rabeprazole/IS). Peak area ratios of the calibration standards were plotted against their nominal concentrations using linear regression analysis $(y=m x+C)$ of spiked calibration standard with the reciprocal of the square of rabeprazole concentration as a weighting factor ( $1 /$ concentration2). Where, $y$ is the peak area ratio, $x$ is concentration, $m$ is slope of the linear and $\mathrm{C}$ is the $\mathrm{y}$-axis intercept value.

\section{System Suitability}

System suitability test was performed at least once on each day prior to method validation experiments. System suitability test comprised of six replicate injections of extracted ULOQ and an extracted blank and LLOQ samples from human plasma.

\section{Specificity and Selectivity}

To evaluate the specificity and selectivity, interference free plasma from six different lots were carried through the sample processing procedure and chromatographed to determine the extent of endogenous plasma components that may contribute to chromatographic interference at the retention time of analyte and internal standard. Selectivity of the method was determined at LLOQ concentration $(0.10 \mathrm{ng} / \mathrm{mL})$. Human plasma extracted samples from six different lots of interference-free blank plasma spiked at LLOQ concentration were analyzed. The signal-to-noise ratio was determined in these samples by comparing mean baseline noise at the vicinity of the retention time of analyte with that of LLOQ peak response.

\section{Carryover}

Auto-sampler carryover was evaluated to determine residual carryover of rabeprazole from a high concentration sample to subsequent sample. To determine the carryover, extracted samples were injected in the following sequence: extracted blank, LLOQ standard, ULOQ standard and re-injection of the same extracted blank. Analyte / internal standard carryover was assessed as percentage of peak area at analyte/internal standard retention time in standard blank to that of analyte/ internal standard peak area in LLOQ standard.

\section{Linearity}

Linearity of rabeprazole in the extracted samples was determined using calibration curves with back calculated concentrations from nine non-zero standards ranging from 0.10 $\mathrm{ng} / \mathrm{mL}$ to $150 \mathrm{ng} / \mathrm{mL}$.

\section{Precision and Accuracy}

Precision and accuracy (P\&A) of the method was evaluated by analyzing rabeprazole in plasma samples (three batches including ruggedness). Each, P\&A batch comprised of a standard blank, standard zero, calibration curve standards and a total of 24 spiked QC samples (6 replicates each of the LOQ, LQC, MQC and HQC samples). Intra-batch/day and Interbatch/day precision and accuracy were also evaluated.

\section{Recovery}

Recovery of rabeprazole from plasma samples was evaluated by comparison of mean area of 6 replicate injections processed in LQC, MQC and HQC samples with mean area from 6 injections of neat (aqueous) solutions. Matrix factor for rabeprazole in human plasma was investigated at LQC and HQC concentrations. Six different lots of post extracted blank plasma samples were spiked at aqueous LQC and HQC; the \%CV for peak area of six post-extracted samples was calculated.

\section{Hemolysis Effect}

To evaluate the hemolysis effect, LQC and HQC samples spiked in interference free haemolysed plasma were processed in 6 replicates and analysed along with freshly prepared CC standards and batch QC samples (in non-haemolysed plasma). This will help to assess the influence of hemolysis on the plasma concentration, which could have happened during sample collection in any clinical study.

\section{Dilution Check}

Six replicates each of the dilution quality control samples were prepared in plasma by spiking dilution quality control stock (DQC) and were further diluted 10 times with interference-free blank plasma prior to analysis and analyzed under precision and accuracy batch. This dilution process is to evaluate the integrity of the unknown concertation in study samples after any such dilution, if made.

\section{Solution Stability}

Stability of rabeprazole solution was assessed for shortterm at ambient temperature and Long-term at refrigerated temperature. 


\section{Matrix Stability}

Rabeprazole stability (bench-top, freeze-thaw, long-term) in plasma was assessed by analyzing six replicates of QC samples spiked at LQC $(0.3 \mathrm{ng} / \mathrm{mL})$ and $\mathrm{HQC}(120 \mathrm{ng} / \mathrm{mL})$ concentration levels, under different storage conditions, thaw cycles and durationof storage.

These stability samples were processed and analyzed under freshly prepared calibration curve standards and quality control samples. The results were compared with nominal/initial concentrations, and the percentage change of concentration was calculated.

\section{Reinjection Reproducibility}

The samples of an accepted precision and accuracy batch were re-analyzed after about 66 hours, which were stored at autosampler temperature (About $5{ }^{\circ} \mathrm{C}$ ). This was to check the reproducibility of the processed samples, after storage.

\section{RESULTS}

\section{System Suitability}

System suitability was assessed based on percentage coefficient of variation $(\% \mathrm{CV})$ for peak area ratio (analyte to internal standard) of six replicate injections at single concentration. The system suitability assessment meets the acceptance limits of $\% \mathrm{CV}$ of $\leq 2 \%$ and retention time was consistent and within \pm 0.5 minutes in each analytical run performed during method validation.

\section{Specificity and Selectivity}

No significant interference was observed at the retention time of rabeprazole and internal standard in six different plasma lots, indicates the specificity of the method. The mean signal-tonoise ratio of Rabeprazole at LOQ level was found to be 13, which meet the acceptance limits of $\geq 5$.

\section{Carryover}

No significant carryover was observed at analyte and internal standard retention times of blank sample re-injected after highest standard injection.

\section{Linearity}

Nine non-zero extracted calibration standards used for the construction of calibration curve met the acceptance criteria in linearity assessment. The correlation coefficient of determination $\left(\mathrm{r}^{2}\right)$ was greater than 0.99 in all the validation runs. The results are presented in Table 1.

\section{Precision and Accuracy}

Intra-batch and Inter-batch precision and accuracy were evaluated, for intra-batch \% CV ranged between 1.18 to $10.0 \%$ with the \%accuracy (\%RE) ranging between 0 to $7.18 \%$. Similarly, Inter-batch \% CV ranged between 2.91 to $10.0 \%$ with the $\%$ accuracy ranging between 0.00 to $2.76 \%$. The results are presented in Table 2 .

\section{Recovery}

Extraction efficiency was calculated as percentage recovery; mean \%recovery values for rabeprazole concentration levels were $69.21 \%$ to $72.44 \%$ over all tested concentration levels. Similarly, the mean recovery value for internal standard at its working concentration was $76.49 \%$.

\section{Matrix Factor}

The matrix factor was within its acceptable limits of $1 \pm 0.15$ and $\% \mathrm{CV}$ was less than $\pm 15 \%$ and hence, it is concluded that the endogenous matrix had no significant impact on the quantification of rabeprazole in plasma.

\section{Haemolysis Effect}

The recovery of Rabeprazole from haemolysed samples was within $\pm 15 \%$ against the normal plasma samples which indicates that the study samples with less than 5\% haemolysis can be quantified accurately.

\section{Dilution Check}

Dilution integrity performed confirmed that study samples can be diluted to a maximum of 10 -fold and quantified accurately, if the study samples concentrations are higher than the linearity range.

\section{Solution Stability}

Aqueous solution of rabeprazole and its internal standard solution found to be stable with less than $10 \%$ from the initial concentration for about 2 days (short-term) at room/ambient temperature and stable for about 2 months (long-term) at refrigerated condition.

Table 1: Calibration Curve and its Summary Data.

\begin{tabular}{|c|c|c|c|c|c|c|c|c|c|c|c|c|}
\hline $\begin{array}{c}\text { Standards Conc. } \\
(\mathrm{ng} / \mathrm{mL})\end{array}$ & $\begin{array}{c}\text { STD1 } \\
\text { 0.10 }\end{array}$ & $\begin{array}{c}\text { STD2 } \\
0.20 \\
\end{array}$ & $\begin{array}{c}\text { STD3 } \\
0.60 \\
\end{array}$ & $\begin{array}{c}\text { STD4 } \\
2.50 \\
\end{array}$ & $\begin{array}{c}\text { STD5 } \\
12.5 \\
\end{array}$ & $\begin{array}{c}\text { STD6 } \\
25\end{array}$ & $\begin{array}{c}\text { STD7 } \\
\mathbf{5 0} \\
\end{array}$ & $\begin{array}{c}\text { STD8 } \\
100\end{array}$ & $\begin{array}{c}\text { STD9 } \\
150\end{array}$ & Slope & Intercept & $\mathbf{r}^{2}$ \\
\hline Run-1 & 0.10 & 0.20 & 0.60 & 2.59 & 12.5 & 25.2 & 49.9 & 99.5 & 143 & 0.01798 & 0.0000803 & 0.9994 \\
\hline Run-2 & 0.10 & 0.20 & 0.60 & 2.50 & 13.0 & 24.9 & 48.6 & 99.2 & 150 & 0.01732 & 0.0000488 & 0.9996 \\
\hline Run-3 & 0.10 & 0.20 & 0.58 & 2.44 & 12.7 & 25.1 & 48.9 & 105 & 150 & 0.02710 & -0.0000815 & 0.9992 \\
\hline Mean $(n=3)$ & 0.10 & 0.20 & 0.59 & 2.51 & 12.7 & 25.1 & 49.1 & 101 & 148 & & & \\
\hline$\% \mathrm{CV}$ & 0.00 & 0.00 & 1.69 & 3.19 & 1.96 & 0.68 & 1.36 & 3.17 & 2.66 & & & \\
\hline \%Accuracy & $\mathbf{0 . 0 0}$ & $\mathbf{0 . 0 0}$ & -1.67 & 0.40 & 2.00 & 0.28 & -1.70 & 1.27 & -1.63 & & & \\
\hline
\end{tabular}


Table 2: Precision and Accuracy of the method.

\begin{tabular}{|c|c|c|c|c|c|}
\hline Run type & Concentration (ng/mL) & LOQ - 0.10 & LQC - 0.30 & MQC- 60 & HQC - 120 \\
\hline \multirow{3}{*}{$\begin{array}{l}\text { Intra-run } \\
\quad(n=6)\end{array}$} & Mean & 0.10 & 0.30 & 64.4 & 121 \\
\hline & $\% \mathrm{CV}$ & 10.0 & 3.33 & 1.18 & 1.63 \\
\hline & $\% \mathrm{RE}$ & 0.00 & 0.00 & 7.18 & 0.35 \\
\hline \multirow{3}{*}{$\begin{array}{c}\text { Inter-run } \\
(n=18)\end{array}$} & Mean & 0.10 & 0.30 & 61.7 & 120 \\
\hline & $\% \mathrm{CV}$ & 10.0 & 3.33 & 3.76 & 2.91 \\
\hline & $\% \mathrm{RE}$ & 0.00 & 0.00 & 2.76 & 0.03 \\
\hline
\end{tabular}

Table 3: Stabilityof Rabeprazole in Human Plasma.

\begin{tabular}{|c|c|c|c|c|c|}
\hline Stability type $(n=6)$ & Stability duration & Storage condition & Concentration (ng/mL) & LQC - 0.30 & HQC - 120 \\
\hline \multirow{2}{*}{ Bench-top } & \multirow{2}{*}{48 hours } & \multirow{2}{*}{$25^{\circ} \mathrm{C}$} & Mean & 0.31 & 126 \\
\hline & & & $\%$ Change & 3.33 & 4.96 \\
\hline \multirow{4}{*}{ Freeze-thaw } & \multirow{2}{*}{5 cycles } & \multirow{2}{*}{$-20^{\circ} \mathrm{C}$} & Mean & 0.31 & 125 \\
\hline & & & $\%$ Change & 3.33 & 4.26 \\
\hline & \multirow{2}{*}{5 cycles } & \multirow{2}{*}{$-70^{\circ} \mathrm{C}$} & Mean & 0.30 & 128 \\
\hline & & & \%Change & 0.00 & 6.74 \\
\hline \multirow{4}{*}{ Long-term } & \multirow{2}{*}{60 days } & \multirow{2}{*}{$-20^{\circ} \mathrm{C}$} & Mean & 0.32 & 130 \\
\hline & & & $\%$ Change & 6.67 & 8.18 \\
\hline & \multirow{2}{*}{60 days } & \multirow{2}{*}{$-70^{\circ} \mathrm{C}$} & Mean & 0.34 & 128 \\
\hline & & & \%Change & 13.3 & 6.94 \\
\hline
\end{tabular}

\section{Matrix Stability}

Rabeprazole spiked in plasma was found to be stable when stored at room temperature at LQC and HQC levels for 48 hours with percentage change of 3.33 and $4.96 \%$.

The $\%$ change of rabeprazole in freeze-thaw samples stored at $-20^{\circ} \mathrm{C}$ and $-70^{\circ} \mathrm{C}$ after five freeze-thaw cycles at LQC and $\mathrm{HQC}$ was found to be 3.33 and $4.26 \%$ (at $-20{ }^{\circ} \mathrm{C}$ ) and 0.00 and $6.74 \%\left(\right.$ at $-70{ }^{\circ} \mathrm{C}$ ), respectively. Rabeprazole was found to be stable in plasma stored at both $-20{ }^{\circ} \mathrm{C}$ and $-70{ }^{\circ} \mathrm{C}$ for up to 56 days at $\mathrm{LQC}$ and $\mathrm{HQC}$. The percentage change in the nominal at LQC stored at $-20^{\circ} \mathrm{C}$ and $-70{ }^{\circ} \mathrm{C}$ was 6.67 and $13.33 \%$, respectively. The percent change in nominal at $\mathrm{HQC}$ stored at $-20^{\circ} \mathrm{C}$ and $-70^{\circ} \mathrm{C}$ was 8.18 and $6.94 \%$, respectively. The results are presented in Table 3.

\section{DISCUSSION}

A simple extraction solvent mixture of n-hexane: tertButyl methyl ether (55:45) was selected based on the polarity of the rabeprazole, has shown reproducible recovery at all the tested levels. Extraction was performed under the neutral condition, as rabeprazole was reported to be degrading at acidic $\mathrm{pH}$ (Shankar and Suneetha, 2014,Zhang et al., 2004 and Jia et al., 2015].The dissociation constant (pKa) of Rabeprazole is 4.5 ; hence extraction was carried out with the phosphate buffer at $\mathrm{pH}$ 7.0, which enable us to extract most of the unionized drug into the extraction solvent. The $\log \mathrm{p}$ value of rabeprazole is 0.55 ; the selected solvent mixture at $\mathrm{pH} 7.0$ has consistent recovery and complies for high throughput.

Rabeprazole is completely ionised in positive mode, due to basic nature (more nitrogen's) of the compound. It was also found that electrospray ionisation produced sufficient signal at the LLOQ level.

Chromatographic conditions were optimised to achieve maximum signal to noise ratio and interference free from the endogenous peaks at rabeprazole and internal standard retention times. Several mobile phase additives were tested in the course of method development and in all the cases, stability of rabeprazole was considered as prime concern. Sufficient efforts were made during optimisation of resolution, run time, sensitivity and reproducibility during. Mobile phase was used for reconstitution before injecting the sample, to maintain the stability of rabeprazole in solution and for better chromatography.

\section{CONCLUSIONS}

In conclusion, a highly sensitive ultra-fast LC-MS/MS method for the quantification of rabeprazole in human plasma was developed and validated. The method is found to be specific, selective, accurate, precise, and linear over the tested concentration range, without interference from the endogenous components, which meets the current industry practice, expectations ofhigh throughput and addresses all the regulatory requirements for the quantification of rabeprazole in human plasma in various clinical studies.

\section{ACKNOWLEDGEMENT}

The author wants to express her gratitude to Dr. G. Viswanathan, Founder and Chancellor VIT University for his constant support and encouragement Sri Sankar Viswanathan, Sri Sekar Viswanathan and Sri G.V Selvam, Vice presidents, VIT University for their constant motivation and Raj Vuppu Temple University, Singapore providing constant help throughout this research.

\section{REFERENCES}

N.V.S. Ramakrishna, K. N. Vishwottam, S. Wishu, M. Koteshwara, S. Suresh Kumar, High-performance liquid chromatography method for the quantification of rabeprazole in human plasma using solidphase extraction. J. Chromatogr. B, 2005, 816:1-2; 209-214

P. Richardson, C.J. Hawkey, W.A. Stack, Proton pump inhibitors. Pharmacology and rationale for use in gastrointestinal disorders. Drugs, 1998, 56:3, 307-335 
H. Nakai, Y. Shimamura, T. Kanazawa, S. Yasuda, M. Kayano, Determination of a new H+-K+ ATPase inhibitor (E3810) and its four metabolites in human plasma by high-performance liquid chromatography. J. Chromatogr. B,1994, 660:1, 211-220

El-Gindy, F. El-Yazby, M.M. Maherv, Spectrophotometric and chromatographic determination of rabeprazole in presence of its degradation products.J. Pharm. Biomed. Anal.,2003, 31:2, 229-242

Y. Zhang, X. Chen, Q. Gu, D.,Zhong, Effects of chronic intermittent hypoxia on the hemodynamics of systemic circulation in rats.Anal. Chim. Acta, 2004, 54:2, 171-174

Shankar S. and Suneetha V., Bioanalytical method for measurement of rabeprazole in human plasma. Der Pharmacia Lettre,2014, $6: 3,277-280$

Y. Zhang, X. Chen, Q. Gu, D., Zhong, Quantification of rabeprazole in human plasma by liquid chromatography-tandem mass spectrometry, Analytica Chimica Acta, 2004, 523,171-175.

C. Lu, Y. Jia, Y.Song, X. Li, Y. Sun, J. Zhao, S. Wang, L.Shi, A. Wen, L. Ding, Application of a LC-MS/MS method to a urinary excretion study of rabeprazole and two of its metabolites in healthy human urine, Journal of Chromatography B, 2015, 988, 75-80.

Jet C. Steene and W. E. Lambert, Comparison of Matrix Effects in HPLC-MS/MS and UPLC-MS/MS Analysis of Nine Basic
Pharmaceuticals in Surface Waters, J Am Soc Mass Spectrom, 2008, 19, 713-718.

Guidance for Industry, Bioanalytical Method Validation, US Department of Health and Human Services Food and Drug Administration, Center for Drug Evaluation and Research (CDER), 2001. Available online at:

http://www.fda.gov/downloads/Drugs/.../Guidances/ucm070107 .pdf

European Medicines Agency, Guideline on the validation of bioanalytical methods. Committee for Proprietary Medicinal Products for Human use (CHPMP), London, UK, 2011,EMEA/CHMP/EWP/192217/2009. Available online at: http://www.ema.europa.eu/docs/en_GB/document_library/Scien tific_guideline/2011/08/WC500109686.pdf

\section{How to cite this article:}

Velan SS, Vuppu S. A Sensitive Ultra-Fast Bioanalytical Method for the Quantification of Rabeprazole in Human Plasma. J App Pharm Sci, 2016; 6 (07): 178-183. 